\title{
Improved Indium-Free Transparent ZnO/Metal/ZnO Electrode through a Statistical Experimental Design Method
}

\author{
Pang Shiu Chen, ${ }^{1}$ Cheng-Hsiung Peng, ${ }^{1}$ Yu-Wei Chang, ${ }^{1}$ Tzu Wei Lin, ${ }^{2,3}$ and S. W. Lee \\ ${ }^{1}$ Department of Chemical and Materials Engineering, MingHsin University of Science and Technology, Hsinfeng, \\ Hsinchu 30401, Taiwan \\ ${ }_{2}^{2}$ Institute of Materials Science and Engineering, National Central University, Chung-Li, Tau Yuan 32001, Taiwan \\ ${ }^{3}$ Chemical Defense Section, Chemical Systems Research Division, Chung-Shan Institute of Science Technology, Long-Tan, \\ Tau Yuan 32547, Taiwan \\ Correspondence should be addressed to Pang Shiu Chen; pschen@must.edu.tw
}

Received 1 November 2015; Revised 3 January 2016; Accepted 13 January 2016

Academic Editor: Somchai Thongtem

Copyright (C) 2016 Pang Shiu Chen et al. This is an open access article distributed under the Creative Commons Attribution License, which permits unrestricted use, distribution, and reproduction in any medium, provided the original work is properly cited.

$\mathrm{ZnO} / \mathrm{Ag} / \mathrm{ZnO}(\mathrm{ZAZ})$ and $\mathrm{ZnO} / \mathrm{Cu} / \mathrm{ZnO}(\mathrm{ZCZ})$ were prepared. The dependence of crystalline, electrical, and optical properties for the multilayer on the postdeposition annealing (PDA) was studied. After PDA of $300^{\circ} \mathrm{C}$ for $20 \mathrm{~min}$, the diffusion of $\mathrm{Cu}$ in $\mathrm{ZnO}$ occurs; this result is responsible for the increasing resistance of the annealed ZCZ. Ag with a thickness of $10 \mathrm{~nm}$ was deposited upon $\mathrm{ZnO}$. The interface of $\mathrm{ZnO}$ and $\mathrm{Ag}$ is clearly revealed by high resolution transmission electron microscopy. The crystalline of $\mathrm{ZnO}$ and $\mathrm{Ag}$ films in the ZAZ with a sheet resistance $\left(R_{s}\right)$ down to $4.17 \Omega / \mathrm{sq}$. The ZAZ layer shows a better thermal stability (up to $400^{\circ} \mathrm{C}$ ) than that of the ZCZ ones. The PDA degraded slightly the optical transmittance and increases the conductivity of ZAZ layer. The figure of merit (FOM) is applied to analysis of the ZAZ layer. The PDA can enhance the FOM of the ZAZ with Ag thickness $>8 \mathrm{~nm}$. The resulting $R_{s}$ and the transmittance ZAZ layers were analyzed by the Taguchi method to obtain the appropriate parameters. The optimized ZAZ has been verified with a $R_{s}$ of $2.3 \Omega / \mathrm{sq}$, a high transmittance (71\%), and the optimal FOM of $1.41 \times$ $10^{-2} \Omega^{-1}$.

\section{Introduction}

Zinc oxide $(\mathrm{ZnO})$ is a compound semiconductor with a direct bandgap of $3.2 \sim 3.37 \mathrm{eV}$ and a lager exciton binding energy of $60 \mathrm{meV}$ at room temperature (RT), which results in potential applications in optoelectronics and solar cells [1-3]. A highly conductive and transparent $\mathrm{ZnO}$ layer can be prepared by doping with group IIIA elements, such as $\mathrm{B}, \mathrm{Al}, \mathrm{Ga}$, and In [4-7]. Doped $\mathrm{ZnO}$ films exhibit good electrical conductivity and optical transmission in the visible region. Although $\mathrm{ZnO}$ : dopant layer has shown low resistance and high transmission characteristics, there is a limitation to an increase in conductivity that can be achieved just by increasing the carrier concentration because of ionized impurity scattering [8]. Hence, $\mathrm{ZnO}$ : dopants films cannot meet the requirement of many applications. $\mathrm{ZnO}$-metal- $\mathrm{ZnO}$ sandwiched structures with different metal midlayer have been explored to the improvement of conductivity without degradation of optical transmission in visible region. The inserted metal layer with low conductivity is required. It is well known that $\mathrm{Au}$ [9], $\mathrm{Al}$ [10], $\mathrm{Cu}$ [11], and $\mathrm{Pt}$ [12] all show good conductivity. Cu layer with advantages of low cost is a good candidate for the metal midlayer. Furthermore, Ag film is demonstrated to be the lowest absorptivity in the visible region for the metal layer [13]. The combination of $\mathrm{Ag}$ and another transparent conductive electrode (TCE) also got a lot of attention recently $[14,15]$. Substrate temperature during the sputtering deposition or postdeposition annealing (PDA) can be used to enhance the $\mathrm{ZnO}$ : dopant layer with low resistance and enough transmittance $[16,17]$. In the report of Sahu and Huang [18], substrate temperature will degrade the resistance of $\mathrm{ZnO}$ and $\mathrm{Ag}$ based multilayer. Till now, there are 
few papers about the thermal stability of the $\mathrm{ZnO}$ multilayers [19]. In this work, the influences of growth parameters on the resistance and optical transmission of $\mathrm{ZnO} / \mathrm{Cu} / \mathrm{ZnO}(\mathrm{ZCZ})$ and $\mathrm{ZnO} / \mathrm{Ag} / \mathrm{ZnO}(\mathrm{ZAZ})$ stacked layer were studied. PDA for the multilayer with different temperatures was also carried out to tailor the transparence and the conductivity of ZCZ and ZAZ films. The ZAZ films show superior thermal stability than that of ZCZ ones.

It has been shown that efficient analyses of productquality characteristics can be achieved using a statistical experimental design method, that is, the Taguchi method, which is a combination of mathematical and statistical techniques used in an empirical study [20-23]. This method has been adopted to optimize various growth parameters and PDA for the ZAZ multilayers due to its potential advantages of experimental efficiency and reproducibility. Therefore, the Taguchi method was utilized in this work to identify the optimal conditions and to select the parameters having the greatest influence on the resistance and optical transmission properties of the resulting ZAZ stacked layer and optimize the performance of transparent conducting ZAZ films by the figure of merits (FOM), which are proposed by Haacke [24].

The objectives of this work were (1) to explore the thermal stability of ZCZ and ZAZ after PDA, (2) to apply the Taguchi method to evaluate the effects of the experimental parameters on the resistance and optical transmittance properties of the resulting ZAZ stacked layer, and (3) to optimize the experimental parameters and carry out a verification experiment using the optimal conditions.

\section{Experimental}

2.1. Preparation and Materials Analysis of $\mathrm{ZnO}$ Multilayers. The $\mathrm{ZnO}$ and $\mathrm{Cu}(\mathrm{Ag})$ multilayers were prepared on corning 1730 glass in a radio-frequency (RF) sputtering system and an evaporation system. The working distance between the substrate and the $\mathrm{ZnO}$ target is $\sim 7 \mathrm{~cm}$. The glass substrates were initially treated by $\mathrm{O}$ plasma induced by $\mathrm{RF}$ plasma of $50 \mathrm{~W}$ for $10 \mathrm{~min}$. Before the deposition of $\mathrm{ZnO}$ layer, the target was cleaned by using Ar plasma for $10 \mathrm{~min}$ to remove target contamination. Then, the samples were coated with $20 \mathrm{~nm}$ thick $\mathrm{ZnO}$ layer as the buffer layers (BL) by sputtering with different power, followed by different thickness of $\mathrm{Cu}$ or Ag embedded layer by evaporation method. Finally, the samples were covered with $\mathrm{ZnO}$ capping layer. Sputtering was performed at RT. The $40 \mathrm{~nm}$ thick $\mathrm{ZnO}$ films were also prepared for comparison. The based pressure of the system reached $5 \times 10^{-6}$ torr. In this study, the sputtering of the $\mathrm{ZnO}$ target was performed at a pressure of 3 mtorr with Ar flow rate of $100 \mathrm{sccm}$. Symbol of $\mathrm{ZA}(n) \mathrm{Z}$ is denoted as the sample with $n$-nm thick Ag layer. Some samples were treated at the temperature range of 150 to $500^{\circ} \mathrm{C}$ for $20 \mathrm{~min}$ to carry out the PDA with the furnace under $\mathrm{N}_{2}$ ambient to explore the thermal stability of ZCZ or ZAZ multilayers.

The structural properties of the multilayer were identified by applying X-ray diffraction (XRD), which was performed on a SIEMENS D5000 X-ray diffractometer with $\mathrm{Cu}-\mathrm{K} \alpha_{1}$ radiation $(\lambda=0.154056 \mathrm{~nm})$. In addition, the crystallite size
TABLE 1: Experimental parameters and corresponding levels used in this study.

\begin{tabular}{lccc}
\hline \multirow{2}{*}{ Experimental parameters } & \multicolumn{3}{c}{ Corresponding levels } \\
& 1 & 2 & 3 \\
\hline A: power of sputtering $(\mathrm{W})$ & 50 & 150 & 300 \\
B: Ag thickness $(\mathrm{nm})$ & 5 & 10 & 15 \\
C: postdeposition annealing $\left({ }^{\circ} \mathrm{C}\right)$ & 200 & 300 & 400 \\
\hline
\end{tabular}

(D) of the stacked films was calculated by the X-ray linebroadening technique performed on the (0002) diffraction of the $\mathrm{ZnO}$ lattice based on the Scherrer formula [25]:

$$
D=\frac{0.9 \lambda}{B \cos \theta_{B}},
$$

where $\theta_{B}$ is the Bragg angle of the diffraction lines, $\lambda$ is the wavelength of the incident $\mathrm{X}$-ray, and $B$ is the full width at half maximum (FWHM). The morphological features and microstructure of the samples were observed with scanning electron microscopy (SEM, JEOL 6500F) and transmission electron microscopy (TEM, Joel JEM-2010). The thickness of the $\mathrm{ZnO}$ multilayer was measured by a surface profiler. The optical properties of the ZAZ multilayer films were characterized by a JASCO V550 spectrometer. The spectral transmittance $(T)$ and reflectance $(R)$ were measured at normal incidence in the wavelength range $\lambda=300-800 \mathrm{~nm}$. The sheet resistance $\left(R_{s}\right)$ of the ZAZ (ZCZ) films was obtained with a four-point probe system. Auger electron spectroscopy (AES) and X-ray photon-electron spectroscopy (XPS) were used to monitor the distribution of $\mathrm{Ag}(\mathrm{Cu})$ atoms in the $\mathrm{ZAZ}$ (ZCZ) stacked layer after PDA of $450^{\circ} \mathrm{C}$ for $20 \mathrm{~min}\left(300^{\circ} \mathrm{C}\right.$ for $20 \mathrm{~min})$.

2.2. Taguchi Design. For the experimental design, we chose to study three parameters that could affect the resistance and transparent properties of the ZAZ stacked layer: the plasma power for the first $\mathrm{ZnO}$ layer, the thickness of inserted $\mathrm{Ag}$ layer, and the temperature of PDA. By using the Taguchi method to optimize the transparent and conductive properties of the ZAZ stacked layer, these three experimental parameters were taken as the controlling factors in the stacked layer; the plasma power for the first $\mathrm{ZnO}$ layer was symbolized as $A(\mathrm{~W})$, the thickness of inserted $\mathrm{Ag}$ layer as $B(\mathrm{~nm})$, and the temperature of PDA as $C\left({ }^{\circ} \mathrm{C}\right)$. Each experimental parameter was varied at three levels for study. The three experimental parameters and their corresponding levels are shown in Table 1 . A template of the $L_{9}\left(3^{4}\right)$ orthogonal array, as given in Liu et al. [20], was selected for study with the Taguchi method, as shown in Table 2. As seen here, there were in total nine experiments needed for this work. Each experiment was repeated three times. Two characteristics of the ZAZ multilayer, that is, the transmittance $\left(T_{i}\right)$ at the wavelength of $550 \mathrm{~nm}$ and the resistance, were selected as the quality characteristics and used for the response analysis. A verification experiment was finally performed to clarify the Taguchi-derived optimum processing conditions. 
TABLE 2: Experimental results and $S / N$ ratios for the resistance $(\Omega / \mathrm{sq})$ and the transmittance $(\%)$ at the wavelength of $550 \mathrm{~nm}$ for $Z A Z$ stacked layers (Taguchi orthogonal array table of $L_{9}\left(3^{4}\right)$ ).

\begin{tabular}{|c|c|c|c|c|c|c|c|c|}
\hline \multirow[t]{2}{*}{ Exp. number } & \multirow[t]{2}{*}{$A(\mathrm{~W})$} & \multirow{2}{*}{$\begin{array}{l}B(\mathrm{~nm}) \\
\text { ted level }\end{array}$} & \multirow{2}{*}{$\begin{array}{l}C\left({ }^{\circ} \mathrm{C}\right) \\
\text { (paramete }\end{array}$} & \multirow{2}{*}{ Error } & \multicolumn{2}{|c|}{$\begin{array}{c}\text { Resistance } \\
\text { (Smaller is better) }\end{array}$} & \multicolumn{2}{|c|}{$\begin{array}{c}\text { Transmittance @ } 550 \mathrm{~nm} \\
\text { (Larger is better) }\end{array}$} \\
\hline & & & & & $\operatorname{Raw}$ data $(\Omega / s q)$ & $S / N$ ratio $(\mathrm{dB})$ & Raw data (\%) & $S / N$ ratio $(\mathrm{dB})$ \\
\hline 1 & $1(50)$ & $1(5)$ & $1(200)$ & 1 & 155.11 & -43.81 & 45 & 33.06 \\
\hline 2 & $1(50)$ & $2(10)$ & $2(300)$ & 2 & 2.83 & -9.04 & 61 & 35.71 \\
\hline 3 & $1(50)$ & $3(15)$ & $3(400)$ & 3 & 5.94 & -15.48 & 47 & 33.44 \\
\hline 4 & $2(150)$ & $1(5)$ & $2(300)$ & 3 & 250.36 & -47.97 & 43 & 32.67 \\
\hline 5 & $2(150)$ & $2(10)$ & $3(400)$ & 1 & 2.54 & -8.10 & 66 & 36.39 \\
\hline 6 & $2(150)$ & $3(15)$ & $1(200)$ & 2 & 4.76 & -13.55 & 50 & 33.98 \\
\hline 7 & $3(300)$ & $1(5)$ & $3(400)$ & 2 & 21.03 & -26.46 & 52 & 34.32 \\
\hline 8 & $3(300)$ & $2(10)$ & $1(200)$ & 3 & 3.69 & -11.34 & 68 & 36.65 \\
\hline 9 & $3(300)$ & $3(15)$ & $2(300)$ & 1 & 2.78 & -8.88 & 56 & 34.96 \\
\hline
\end{tabular}

\section{Results and Discussion}

3.1. Microstructures and Basic Characterizations of ZnO Films. The dependence of growth rate of the $\mathrm{ZnO}$ films on the $\mathrm{RF}$ plasma power in this work is depicted in Figure 1. The film thickness of $40 \mathrm{~nm}$ for each RF power is prepared for comparison. The evolution of XRD spectra of the $40 \mathrm{~nm}$ thick films on different RF plasma power is shown in Figure 2. The $\mathrm{ZnO}$ film exhibits a strong diffraction peak at about $2 \theta=$ $33.7^{\circ}$, which is associated with the (0002) plane of hexagonal phase $\mathrm{ZnO}$ [JCPDS, Card 04-0783] and indicated that all of the obtained $\mathrm{ZnO}$ layers at RT are polycrystalline. On increasing of the sputtering power, the FWHM of the X-ray spectrum slightly increase. This result is consistent with that of Lu et al. [26]. By the Scherrer formula, the grain size of the $\mathrm{ZnO}$ films can be derived as $13 \sim 15 \mathrm{~nm}$. The asymmetric $\mathrm{O} 1 \mathrm{~s}$ peak was fitted by two nearly Gaussian components, centered at 530.2 and $531.4 \mathrm{eV}$, respectively, as shown in Figure 3. There are some nonlattice $\mathrm{O}$ atoms in the matrix of as-prepared $\mathrm{ZnO}$ films by sputtering [27], which suggest that there are some defects in the sputtered $\mathrm{ZnO}$ films.

3.2. ZCZ Multilayers. The compositional profiles revealed by AES for as-prepared ZCZ with an $8 \mathrm{~nm}$ thickness $\mathrm{Cu}$ layer and annealed ones after $300^{\circ} \mathrm{C}$ for $20 \mathrm{~min}$ are presented (Figure 4(a)). In Figure 4(a), the position of $\mathrm{Cu}$ interlayer is located at the upper $\mathrm{ZnO}$ layer and the bottom one in the as-grown ZCZ layer. However, for the annealed sample (Figure 4(a)), the out-diffusion of $\mathrm{Cu}$ atoms from the $\mathrm{ZnO}$ matrix is obviously observed. The formation of $\mathrm{Cu}$ based oxide on the surface of $\mathrm{ZnO}$ film, which is clarified by XRD (not shown here), is also found. The dependence of the resistance of ZCZ on the annealing temperature is depicted in Figure 4(b). In the report of Yang et al. [28], the $\mathrm{Cu}$ atoms were observed to lose their electrons and become $\mathrm{Cu}^{2+}$ ions after annealing. The resistance of the ZCZ stacked layer increases as the samples under PDA temperature $>300^{\circ} \mathrm{C}$. These charged $\mathrm{Cu}$ ions may be the scattering centers, which reduce the conductivity of the ZCZ multilayers [7]. According to the dependence of the $\mathrm{Cu}$ compositional profile and resistance in

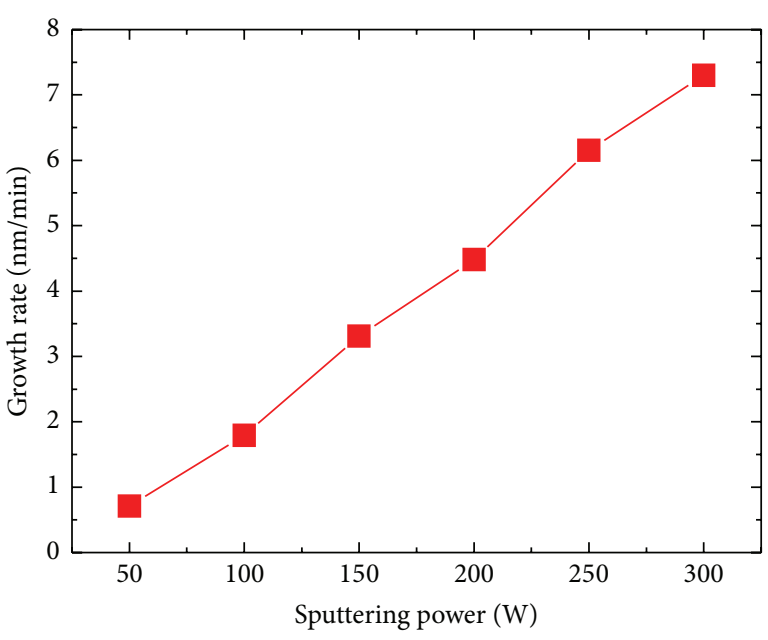

FIgURE 1: Growth rate of $\mathrm{ZnO}$ films grown at $\mathrm{RT}$ as a function of $\mathrm{RF}$ power.

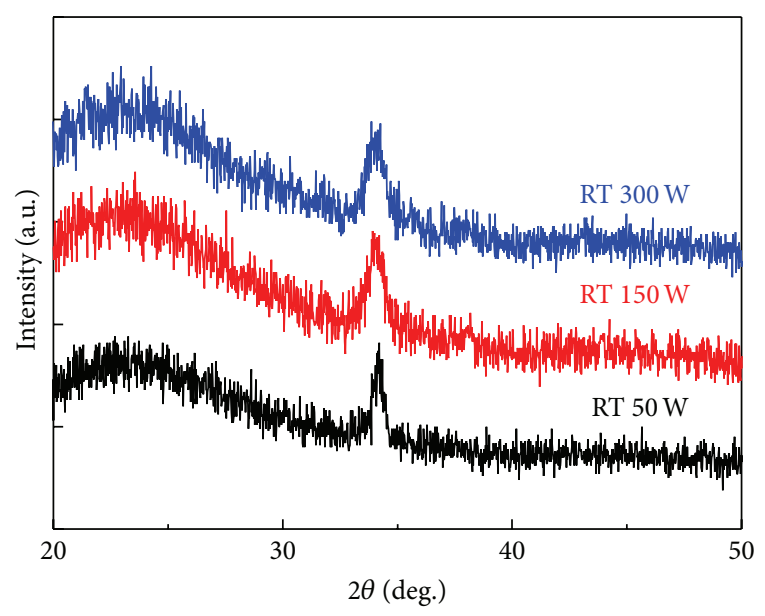

FIgURE 2: X-ray diffraction spectra of $\mathrm{ZnO}$ films grown by using RF power of 50,150, and $300 \mathrm{~W}$. 


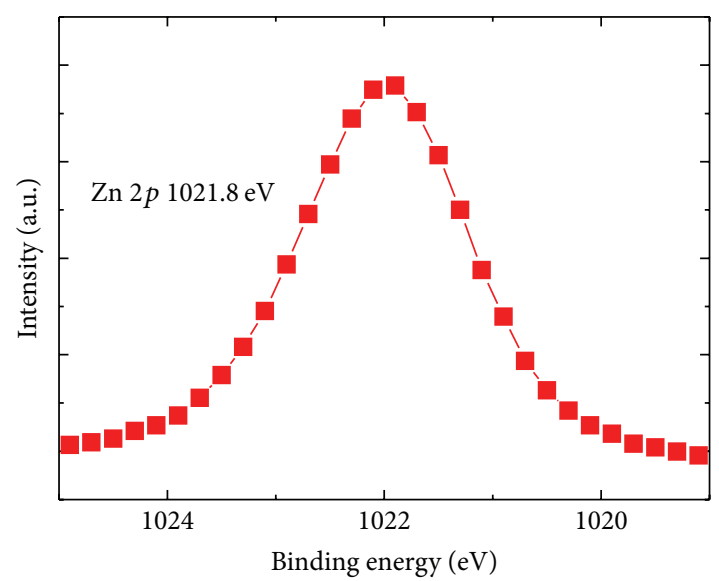

(a)

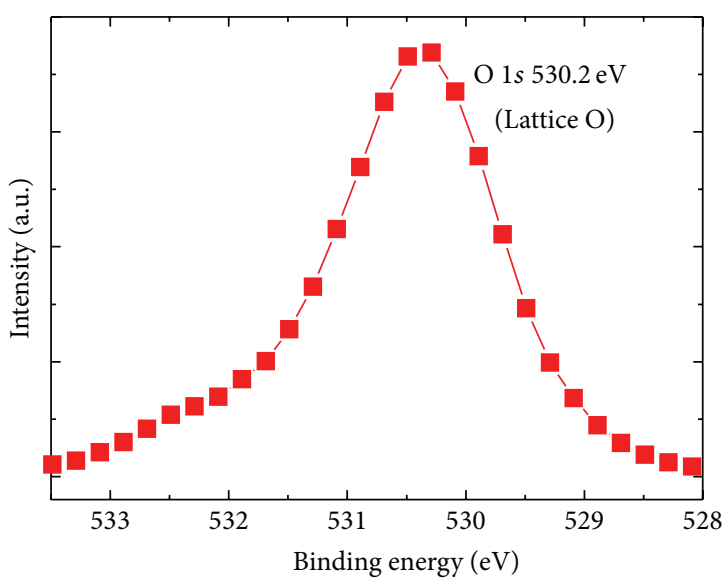

(b)

FIgURE 3: The XPS spectra of (a) Zn $2 p$ and (b) O $1 s$ core levels in the ZnO layer by using sputtering. Some nonlattice oxygen ions were observed in the $\mathrm{ZnO}$ films.

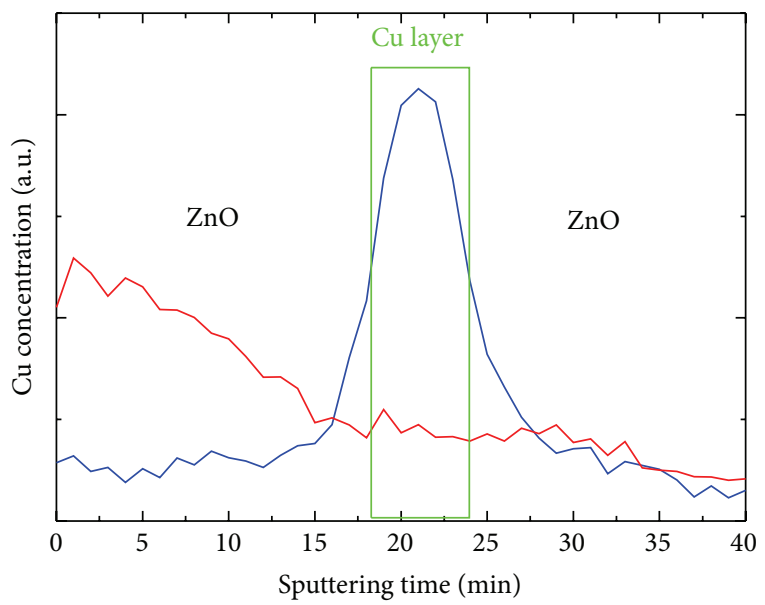

(1) As-prepared

(2) $300^{\circ} \mathrm{C}, 20 \mathrm{~min}$

(a)

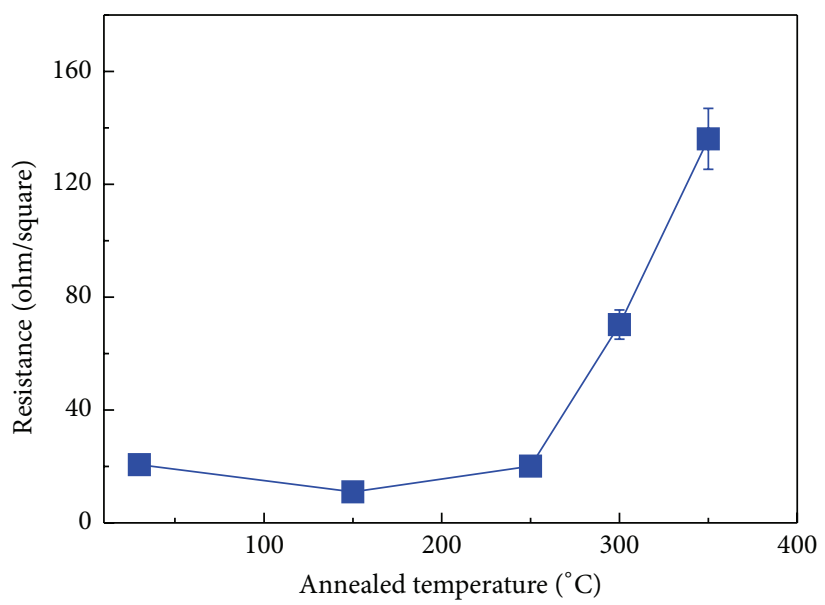

(b)

Figure 4: (a) Depth profile of $\mathrm{Cu}$ ion in the ZCZ multilayer as-prepared and after annealing at $300^{\circ} \mathrm{C}$ for 20 min and (b) dependence of resistance of $\mathrm{ZCZ}$ on the postannealing temperature.

the ZCZ stacked layer on the PDA temperature, the thermal stability of $\mathrm{Cu}$ is poor. High PDA temperature leads to increase in the resistance of ZCZ sandwiched structure; the diffusion of $\mathrm{Cu}$ in the $\mathrm{ZnO}$ matrix is responsible for this result.

3.3. ZAZ Multilayers. The optimization of Ag thickness in the ZAZ multilayer is reported to be important for a high quality transparent electrode $[18,29]$. The UV-Vis spectra of AZ (Figure 5(a)) and ZAZ (Figure 5(b)) multilayers with different Ag thickness after different temperature of PDA are shown. In the AZ series samples, their optical transmittance at $550 \mathrm{~nm}$ value decreases with the increasing thickness of the Ag layer (see Figure 5(c)). However, the insert of a $10 \mathrm{~nm}$ thick Ag layer leads to an increase in the optical transmittance of
$71.05 \%$ at a wavelength of $550 \mathrm{~nm}$ as shown in Figure 5(c). The $5 \mathrm{~nm}$ Ag layer in the ZAZ stacked layer plays a role as a reflector, which suppresses its visible transmittance $(41 \%$ at $550 \mathrm{~nm}$ ). However, further increasing the Ag thickness above $15 \mathrm{~nm}$ resulted in a decrease in the transmittance. With enough thickness, the Ag layer may create an amplified electric field through the metal surface plasmon resonance [30]. This result may be responsible for the increase of the visible transmittance of ZAZ layer with a $10 \mathrm{~nm}$ thick $\mathrm{Ag}$. The Ag/ZnO layer with an identical Ag thickness also shows a lower optical transmittance than that of ZAZ multilayer. Figure 6(a) shows the cross-sectional TEM images of the ZAZ multilayer with $10 \mathrm{~nm}$ thick $\mathrm{Ag}$ and the diffraction pattern of $\mathrm{ZnO}$ is presented in Figure 6(b). The ZAZ clearly revealed well-defined $\mathrm{ZnO}$ and $\mathrm{Ag}$ layers without the formation of an 


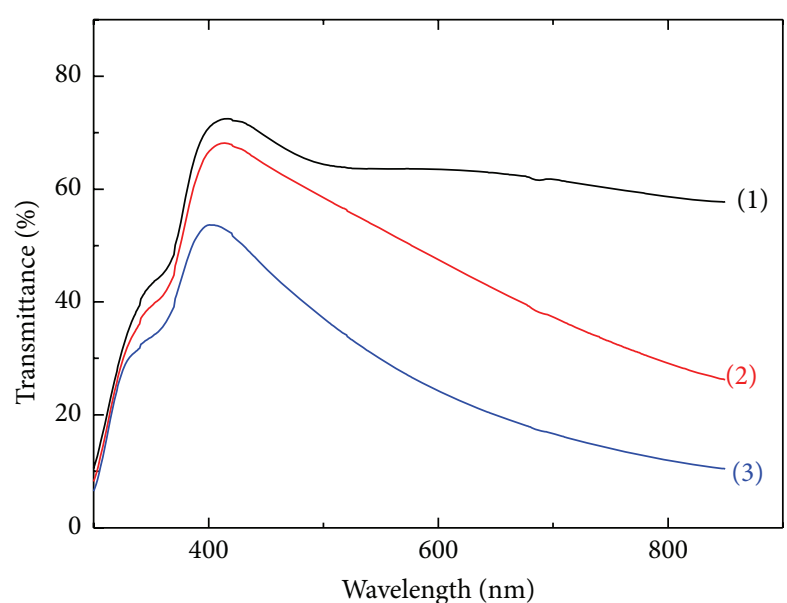

(1) $5 \mathrm{~nm}$

(2) $10 \mathrm{~nm}$

(3) $15 \mathrm{~nm}$

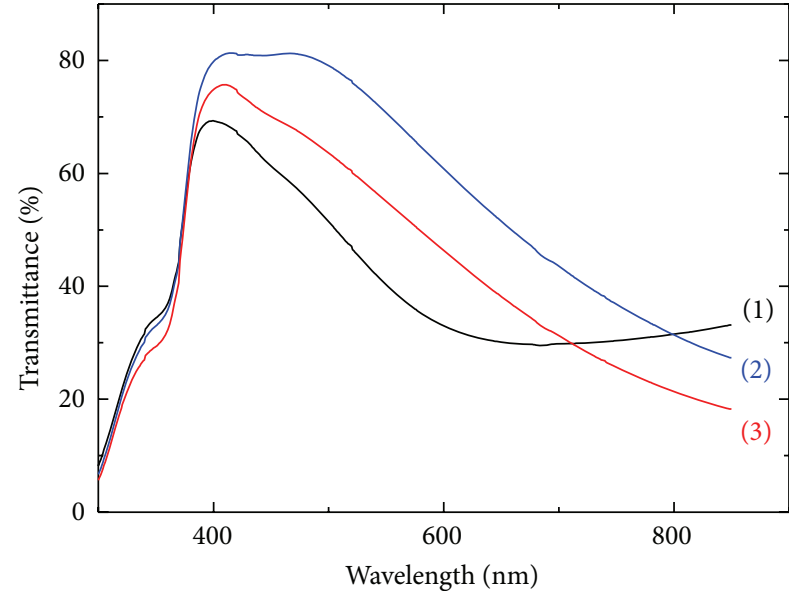

(1) $5 \mathrm{~nm}$

(2) $10 \mathrm{~nm}$

(3) $15 \mathrm{~nm}$

(a)

(b)

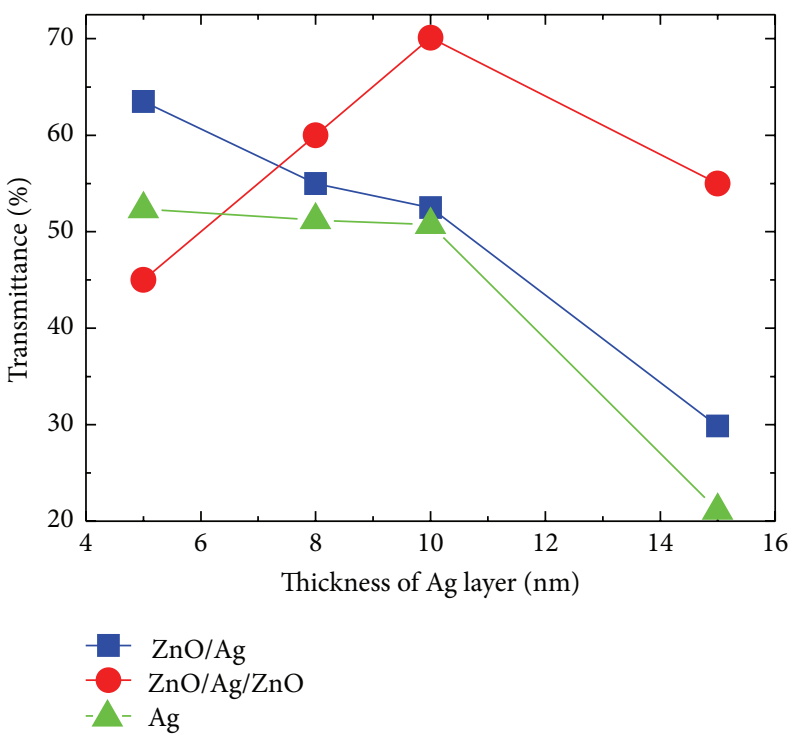

(c)

FIGURE 5: Dependence of transmittance of (a) AZ and (b) ZAZ on the thickness of the inserted Ag films and (c) transmittance at the wavelength of $550 \mathrm{~nm}$ of Ag, ZA, and ZAZ as a function of the Ag thickness.

interface layer. There is no evidence of an interfacial reaction between the $\mathrm{Ag}$ and $\mathrm{ZnO}$ layers due to the stability of the coexistence of $\mathrm{ZnO}$ and $\mathrm{Ag}$ layers at $\mathrm{RT}$. Considering the formation enthalpy of $\mathrm{ZnO}(350.4 \mathrm{~kJ} / \mathrm{mol})$, the dissociation of $\mathrm{ZnO}$ by the formation of $\mathrm{Ag}_{2} \mathrm{O}(31.1 \mathrm{~kJ} / \mathrm{mol})$ layer cannot easily occur [31]. All the microstructures of $\mathrm{ZnO}$ layers in the ZAZ show polycrystalline as confirmed by the X-ray spectra. However, the Ag layer sandwiched between the $\mathrm{ZnO}$ layers showed a crystalline structure with a (111) preferred orientation, as expected from the XRD result discussed later, even though it was grown at RT. The Ag film also forms a continuous layer, which is beneficial for the resistance of the stacked layer and discussed later.
The X-ray diffraction spectra of ZAZ films with various Ag thicknesses of 5, 10, and $15 \mathrm{~nm}$ are present in Figure 7(a). The $\mathrm{ZnO}$ BL were grown by using RF power of $150 \mathrm{~W}$. And Figure 7(b) shows the dependence of resistance and FOM of the ZAZ on the inserted Ag thickness. The XRD pattern for the ZAZ stacked layer had different Ag thickness (5, 10 , and $15 \mathrm{~nm}$ ). The peak around $33.7^{\circ}$ belongs to the $\mathrm{ZnO}$ (0002) and the peak observed around $38.35^{\circ}$ corresponds to the Ag (111) peak. The FWHM and intensity of X-ray spectrum for ZA(5)Z layer seem to be wider and lower than those of one with $10(15) \mathrm{nm}$. This result suggested that the $5 \mathrm{~nm}$ thick $\mathrm{Ag}$ above $\mathrm{ZnO}$ BL will degrade the crystalline of the successive $\mathrm{ZnO}$ top layer. The resistance 


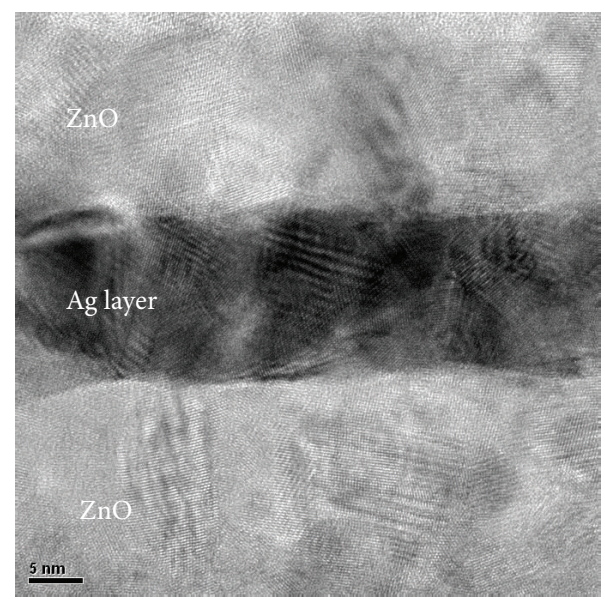

(a)

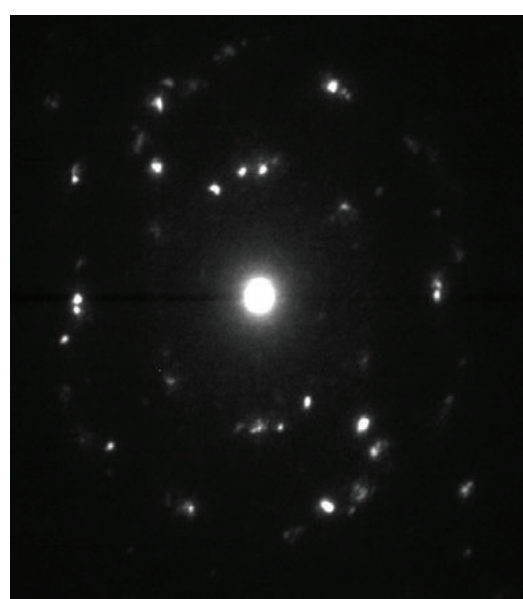

(b)

FIGURE 6: (a) Cross-sectional TEM images of the ZA(10)Z stacked layer and (b) the diffraction pattern of ZnO in ZAZ stacking layer.

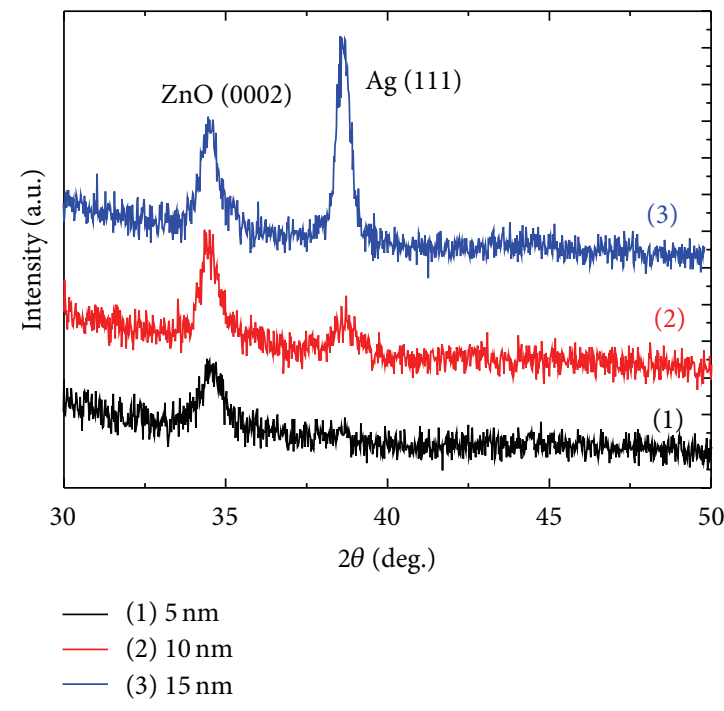

(a)

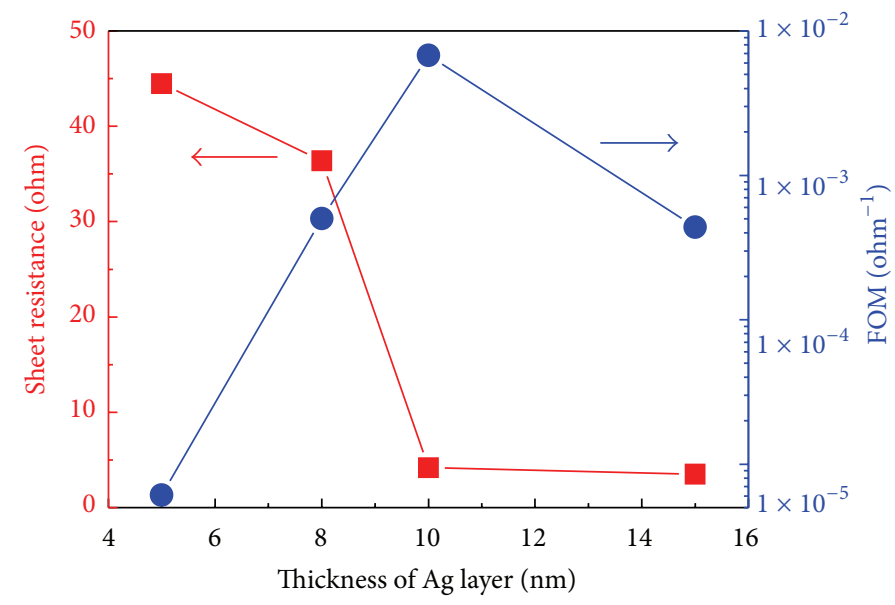

(b)

FIGURE 7: (a) X-ray diffraction spectra of ZAZ films with various Ag thicknesses of 5, 10, and $15 \mathrm{~nm}$ grown by using RF power of $150 \mathrm{~W}$ and (b) the dependence of resistance and FOM of the ZAZ on the inserted Ag thickness.

of as-prepared $\mathrm{ZnO}$ film is higher than $0.14 \mathrm{G} \Omega$. A high quality of as-grown ZAZ stacked layer that consisted of a $5 \mathrm{~nm}$ thick Ag layer with $R_{s}$ as low as $45 \Omega$ /sq was obtained and could be reproduced by controlling the preparation process parameters. The resistance of ZAZ multilayers was reduced effectively by an increasing thickness of the inserted $\mathrm{Ag}$ film as shown in Figure 7(b). Finally, the performance of the ZAZ multilayers as transparent conducting materials was also compared using FOM. The FOM for all the multilayers after PDA for the application of transparent conductive electrode are calculated using the formulas as follows:

$$
F_{\mathrm{tc}}=\frac{T^{10}}{R_{s}},
$$

where $T$ is the transmittance at $550 \mathrm{~nm}$ and $R_{s}$ is sheet resistance of the multilayer coatings [24]. The $\mathrm{ZA}(10) \mathrm{Z}$ grown at RT owns the highest FOM of $6.7 \times 10^{-3} \Omega^{-1}$.

The thermal stability of ZAZ multilayers was also studied. The compositional depth profiles revealed by the AES results obtained from the ZAZ sample on glass with or without PDA $\left(400^{\circ} \mathrm{C}\right.$ for $\left.20 \mathrm{~min}\right)$ are presented in Figure 8 . The compositional profiles of $\mathrm{Ag}$ atoms seem insensitive of the annealing treatment $\left(<400^{\circ} \mathrm{C}\right.$ for $\left.20 \mathrm{~min}\right)$. The thermal stability of ZAZ sandwiched structure is superior to that of ZCZ one (comparing Figures 4(a) and 8). The X-ray spectra of $\mathrm{ZA}(10) \mathrm{Z}$ under different annealing temperature are presented in Figure 9(a). After PDA of $400^{\circ} \mathrm{C}$ for $20 \mathrm{~min}$, the peak of $\mathrm{ZnO}$ (0002) shifts to high Bragg's angle (34.4 ${ }^{\circ}$, which suggests that the as-prepared $\mathrm{ZnO}$ film is under compressive 


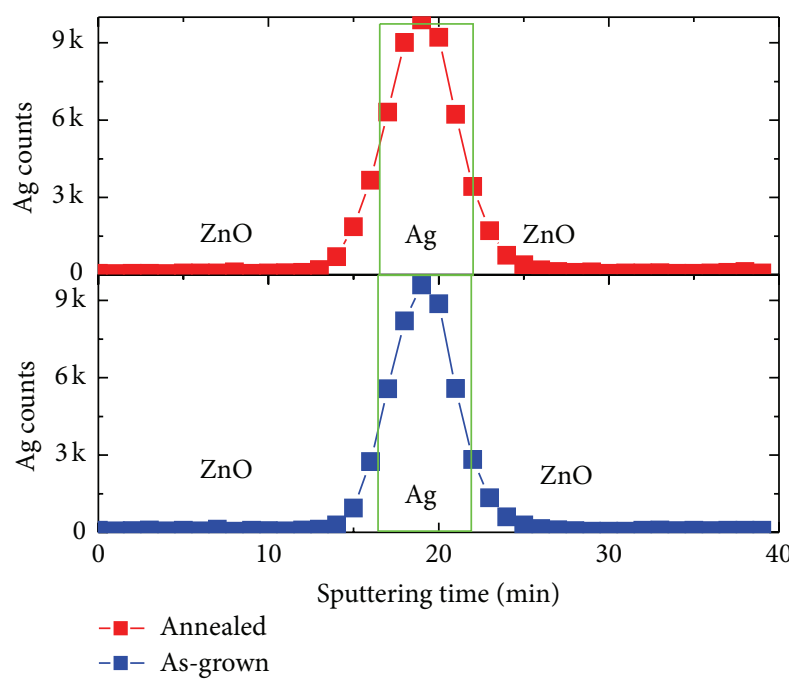

FIGURE 8: Depth profile of Ag species in the ZAZ multilayer asprepared and after annealing for $400^{\circ} \mathrm{C}$ for $20 \mathrm{~min}$.

stress along the in-plane direction. The PDA treatment can reduce the strain of $\mathrm{ZnO}$. The FWHM of $\mathrm{Ag}$ (111) decrease with the increasing PDA temperature (Figure 9(b)), which can improve the crystalline of the inserted Ag layer. The grain size of $\mathrm{ZnO}$ also enlarge with the increasing of PDA temperature. The surface roughness in the ZAZ stacked layer increases with the increasing of high PDA temperature $\left(>200^{\circ} \mathrm{C}\right)$ (not shown here). The visible transmittance and resistance and roughness of $\mathrm{ZA}(8) \mathrm{Z}$ films as a function of PDA temperature are presented in Figures 10(a)-10(b). The wavelength of visible light @ $550 \mathrm{~nm}$ decreases with the increasing of PDA temperature up to $200^{\circ} \mathrm{C}$. Some broken $\mathrm{ZnO}$ and $\mathrm{Ag}$ films were observed on the surface of $\mathrm{ZAZ}$ multilayer treated with the PDA temperature $>500^{\circ} \mathrm{C}$, which leads to the abrupt increase of their visible transparency in the range from 400 to $800 \mathrm{~nm}$ (Figure 10(a)); however, their $R_{s}$ value is out of range for the instrument, and the discontinuous Ag layer induced by PDA may be responsible for this result. However, the conductivity of the multilayer exhibits a different tendency, as shown in Figure 10(b). An enough PDA treatment up to $400^{\circ} \mathrm{C}$ for $20 \mathrm{~min}$ will be beneficial for the reduction of resistance of the multistack with retained visible transmittance. These results also suggest that the degradation of transparence in the ZAZ layer may be due to rough surface or scattering by the free carriers in the $\mathrm{ZnO}$ matrix [18].

The Ag thickness was also found to be a strong function of FOM after thermal treatment in the ITO and Ag stacked layer [32]. In Figure 10(c), the FOM of Ag thickness in ZAZ multilayer is 8 or $10 \mathrm{~nm}$, respectively. The film with $\mathrm{ZA}(8) \mathrm{Z}$ after PDA of $400^{\circ} \mathrm{C}$ for $20 \mathrm{~min}$ has the highest FOM value of $9.2 \times 10^{-4} \Omega^{-1}$. The inserted Ag layer with $10 \mathrm{~nm}$ thick can improve the FOM of the multilayer of ZAZ. Maintenance of enough visible transmittance and low $R_{s}$ induced by the $10 \mathrm{~nm}$ thick $\mathrm{Ag}$ are responsible for this result. The highest FOM of ZA(10)Z multilayer after PDA of $200^{\circ} \mathrm{C}$ for $20 \mathrm{~min}$ is $\sim 1.25 \times 10^{-2} \Omega^{-1}$. In this work, enough PDA treatment can increase the FOM of ZAZ with enough thickness of Ag film; however, it is desirable to carry out a design of experiment to find optimum parameters for the preparation of ZAZ layers under a PDA treatment.

3.4. Taguchi Method Analysis for the ZAZ Multilayers under $P D A$. The Taguchi method provides the user to determine the optimum experimental conditions having the least variability. In this work, the signal-to-noise $(S / N)$ ratio is adopted to obtain the deviation of the selected quality properties from their target values. The experimental results with the maximum $S / N$ ratio are thus considered as the optimal conditions. The $S / N$ ratio is defined as

$$
\frac{S}{N} \text { ratio }=-10 \log (\mathrm{MSD}) \quad(\text { unit: decibel }(\mathrm{dB}))
$$

where the MSD is the mean squared deviation from the desired value of the output characteristic [19]. The value of the $S / N$ ratio is desired to be maximized; therefore, the value of the MSD needs to be minimized. The MSD is defined differently for each of the three quality characteristics considered: namely, bigger is better, smaller is better, and nominal is better. In this section, the response analyses of the $S / N$ ratios are used to figure out the optimum results for the preparation of ZAZ multilayers with low resistance and high optical transmission (i.e., a larger $T_{i}$ value at the wavelength of $550 \mathrm{~nm}$ ). The former feature is the characteristic of smaller is better, while the latter one is attributed to the bigger is better response. Their MSD values are, respectively, defined as [21]

$$
\begin{aligned}
& \mathrm{MSD}=\frac{1}{n} \sum_{i=1}^{n} y_{i}^{2}, \\
& \mathrm{MSD}=\frac{1}{n} \sum_{i=1}^{n} \frac{1}{y_{i}^{2}},
\end{aligned}
$$

where $y_{i}$ is the result of experiment $i$ and $n$ is the sample size $i$.

In Section 3.3, the experimental results present that the resistance and transparence in the visible region of the resulting ZAZ sandwiched structure could be determined by the inserted Ag thickness, the sputtering power of $\mathrm{ZnO}$ $\mathrm{BL}$, and the PDA temperature. The raw data and the corresponding $S / N$ ratios for the resistance and the $T_{i}$ value of the nine designed experiments, calculated using (3)(5), are listed in Table 2. The average $S / N$ ratios for each experimental parameter at each level are summarized, and the $S / N$ responses for the resistance and the $T_{i}$ values are shown in Table 3 . The $S / N$ response to each parameter level is shown in Figure 11. Here, a higher $S / N$ ratio indicates a larger contribution by given experimental conditions at the level to the objective function. Moreover, greater slopes of the connecting lines of the $S / N$ ratios indicate larger effects of the experimental parameters on the objective function. Therefore, the optimum conditions for the resistance are factor $A$ at level 3, $B$ at level 2, and $C$ at level 3, whereas those for the $T_{i}$ value are also $A$ at level 3, $B$ at level 2, and $C$ at level 3. 


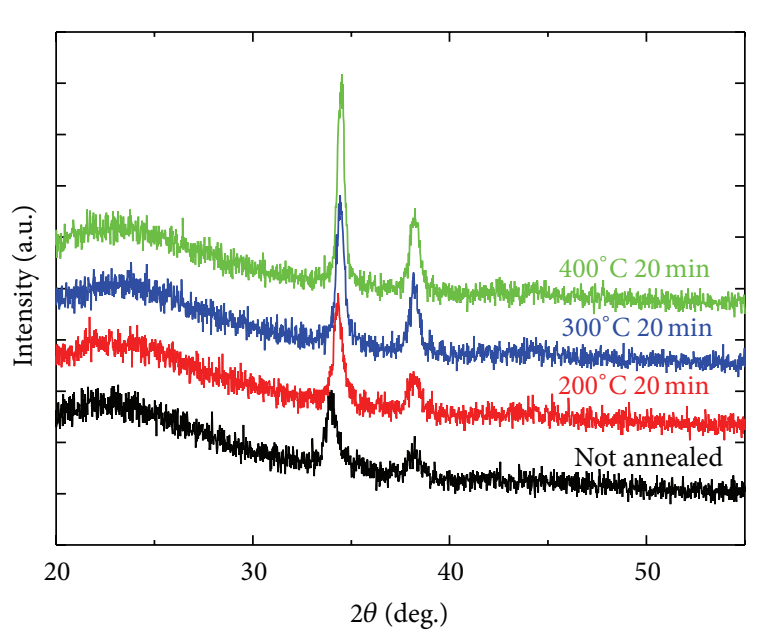

(a)

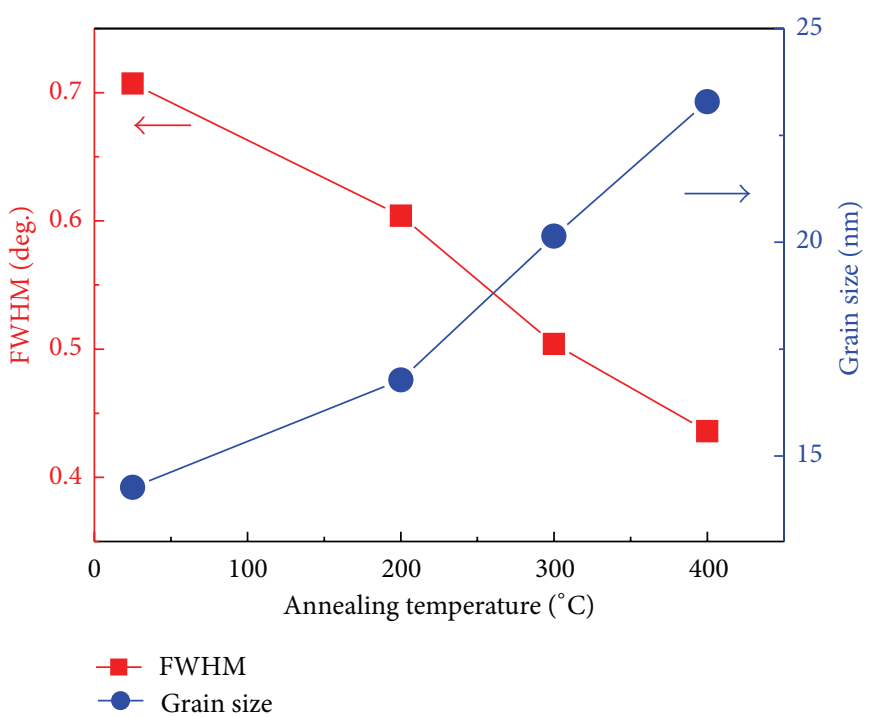

(b)

FIGURE 9: (a) X-ray diffraction spectra and (b) the FWHM of $\mathrm{ZnO}$ (0002) and grain size in the ZA(10)Z films as a function of annealing temperature.

TABLE 3: $S / N$ ratio responses for each experimental parameter at each level.

\begin{tabular}{|c|c|c|c|c|c|c|}
\hline \multirow{2}{*}{ Experimental parameters } & \multicolumn{3}{|c|}{ Mean $S / N$ ratio for resistance $(\mathrm{dB})$} & \multicolumn{3}{|c|}{ Mean $S / N$ ratio for $T_{i}(\mathrm{~dB})$} \\
\hline & Level 1 & Level 2 & Level 3 & Level 1 & Level 2 & Level 3 \\
\hline $\bar{A}$ & -22.77 & -23.21 & -15.56 & 34.07 & 34.35 & 35.31 \\
\hline$B$ & -39.41 & -9.49 & -12.64 & 33.35 & 36.25 & 34.13 \\
\hline C & -22.90 & -21.96 & -16.68 & 34.56 & 34.45 & 34.72 \\
\hline
\end{tabular}

3.5. Prediction and Confirmation of ZAZ Stacked Layer Properties. According to the definition of FOM with high value, the transmittance value of the $\mathrm{ZAZ}$ is more significant than their resistance value. To prepare $\mathrm{ZnO}$ and $\mathrm{Ag}$ multilayers with a low $R_{s}$ and large $T_{i}$ value, the $\mathrm{Ag}$ thicknesses were selected as $10 \mathrm{~nm}$, as the experimental condition of $10 \mathrm{~nm}$ gave rise to the largest $S / N$ ratio (36.25) in the $T_{i}$ value as well as the reasonable $S / N$ ratio in the $R_{s}$ value (see Table 3 ). The adoption of the other experimental condition of PDA of $400^{\circ} \mathrm{C}$ was used to obtain an acceptable resistance value. It is thus suggested that $300 \mathrm{~W}$ of plasma power $(A 3)$, an inserted $10 \mathrm{~nm}$ thick Ag film (B2), and PDA temperature of $400^{\circ} \mathrm{C}(\mathrm{C} 3)$ could be the optimal conditions based on the consideration of processing economics.

The predicted $S / N$ ratio using the appropriate levels of the experimental parameters can be calculated as

$$
\begin{aligned}
& \frac{S}{N_{\text {predicted }}}=\frac{S}{N_{\text {average }}}+\left[\left(\frac{S}{N_{A 3, \text { mean }}}-\frac{S}{N_{\text {average }}}\right)\right. \\
& +\left(\frac{S}{N_{B 2 \text {, mean }}}-\frac{S}{N_{\text {average }}}\right) \\
& \left.+\left(\frac{S}{N_{C 3 \text {, mean }}}-\frac{S}{N_{\text {average }}}\right)\right],
\end{aligned}
$$

where $S / N_{\text {average }}$ is the total average $S / N$ ratio, whereas $S / N_{A 3 \text {, mean }}, S / N_{B 2 \text {,mean, }}$ and $S / N_{C 3 \text {,mean }}$ are the mean $S / N$ ratios at the optimal level of each experimental parameter. In the case of resistance, the value of $S / N_{\text {average }}$ calculated from Table 2 is $(-20.51)$. The $S / N_{A 3 \text {,mean }} S / N_{B 2 \text {,mean }}$, and $S / N_{C 3 \text {,mean }}$ values in Table 3 are $-15.56,-9.49$, and -16.68 , respectively. With these values, the above equation can be rewritten as

$$
\begin{aligned}
& \frac{S}{N_{\text {predicted }}}=-20.51+[(-15.56+20.51) \\
& \quad+(-9.49+20.51)+(-16.68+20.51)]
\end{aligned}
$$

and the predicted $S / N$ ratio $(-0.71)$ for crystalline size can thus be obtained. Then, the corresponding estimated crystalline size can be derived from (5): that is,

$$
-0.71=-10 \log \left[y^{2}\right]
$$

and the estimated $R_{s}(1.08 \Omega / \mathrm{sq})$ can be obtained. Both the predicted $S / N$ ratio for the $T_{i}$ (37.12) and the estimated $R_{i}$ value $(71.8 \%)$ can be calculated through a similar procedure with the "larger is better" analysis. Table 4 shows the comparison of the resistance and transmittance of the ZAZ stacked layer with the experimental results by using the optimal conditions. 


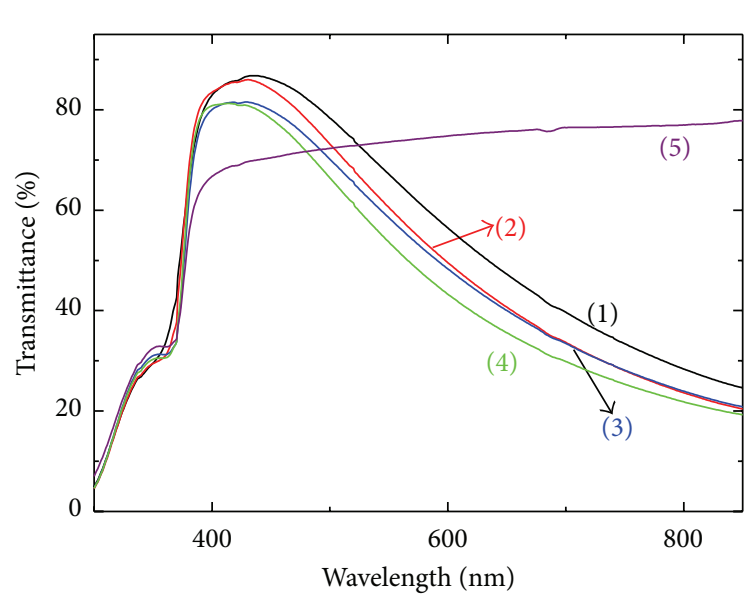

(1) As-prepared
- (2) $200^{\circ} \mathrm{C}$
(3) $300^{\circ} \mathrm{C}$

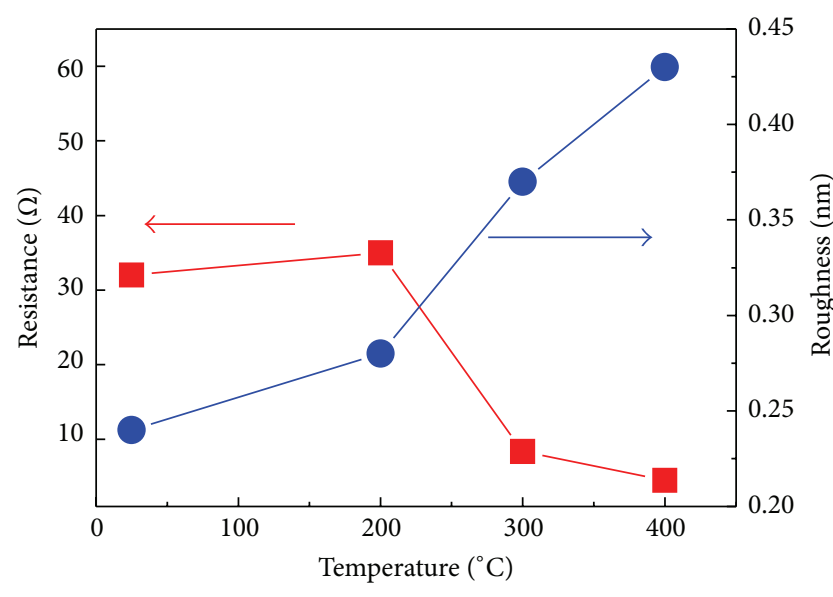

Resistance

Roughness

(a)

(b)

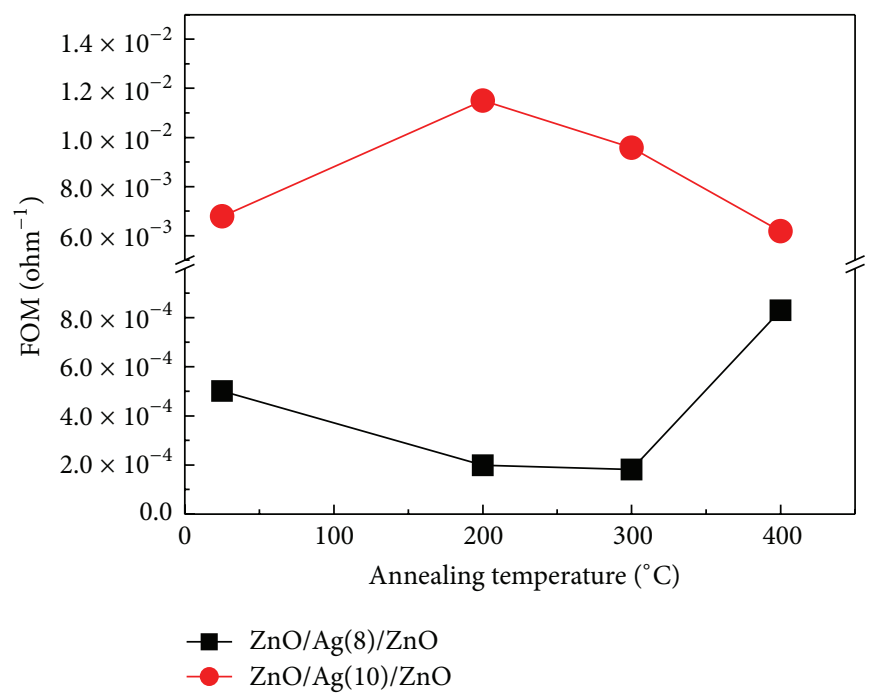

(c)

Figure 10: (a) Visible transmittance and (b) resistance and roughness of ZA(8)Z films as a function of PDA temperature and (c) FOM of $\mathrm{ZA}(10) \mathrm{Z}$ and $\mathrm{ZA}(8) \mathrm{Z}$ as a function of PDA temperature.

TABLE 4: Comparison of the predicted resistance $(\Omega / \mathrm{sq})$ and transmittance value (\%) for the ZAZ multilayers with the experimental results using the optimal experimental parameters.

\begin{tabular}{lcccccc}
\hline Condition & & \multicolumn{2}{c}{$\begin{array}{l}\text { Resistance }(\Omega / \mathrm{sq}) \\
(\text { Smaller is better })\end{array}$} & & \multicolumn{2}{c}{$\begin{array}{c}T_{i} \text { at } 550 \mathrm{~nm} \\
(\text { Larger is better })\end{array}$} \\
& Level & Raw data & $S / N$ ratio $(\mathrm{dB})$ & Level & Raw data & $S / N$ ratio $(\mathrm{dB})$ \\
\hline Prediction & $A 3 B 2 C 3$ & 1.08 & -0.71 & $A 3 B 2 C 3$ & 71.8 & 37.12 \\
Confirmed experiment & $A 3 B 2 C 3$ & 2.3 & -7.23 & $A 3 B 2 C 3$ & 71 & 37.02 \\
\hline
\end{tabular}

Although the resistance of ZAZ obtained from the confirmation experiment $(2.3 \Omega / \mathrm{sq})$ was slightly higher than the predicted $(1.08 \Omega / \mathrm{sq})$, they were all roughly consistent. According to the transmittance spectra observations (see Figure 12), the actual transmittance of the ZAZ at the wavelength of $550 \mathrm{~nm}$ with the optimal conditions was estimated to be $\sim 71 \%$. As presented in Table 4 , there was a good agreement between the predicted and experimental optical transmittance values at $550 \mathrm{~nm}$. Consequently, it was confirmed that the $R_{s}$ and the $T_{i}$ values of the ZAZ with appropriate PDA treatment can be concurrently reduced and increased with the Taguchi method. By adopting the $R_{s}$ 


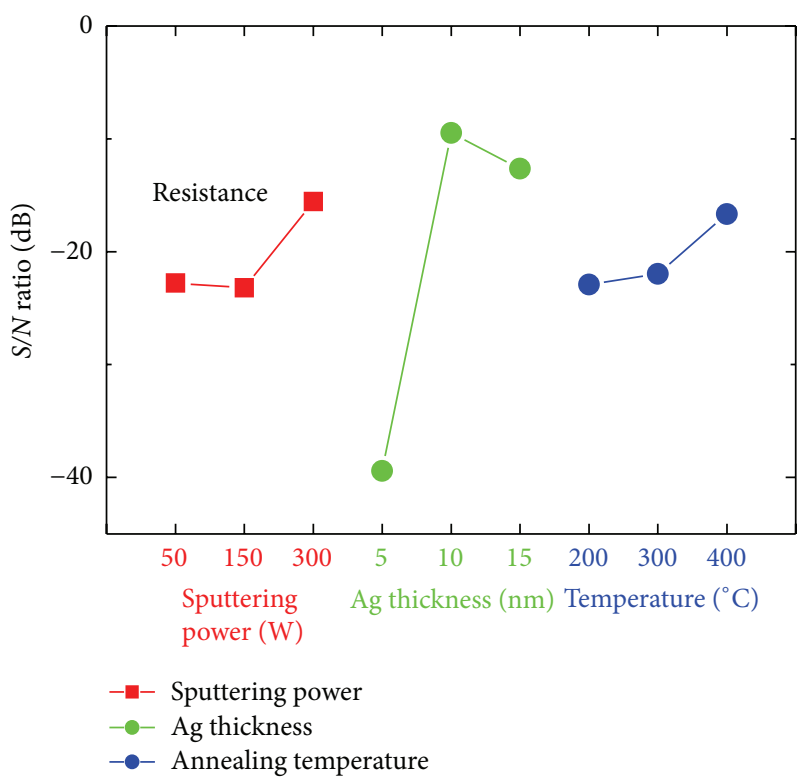

(a)

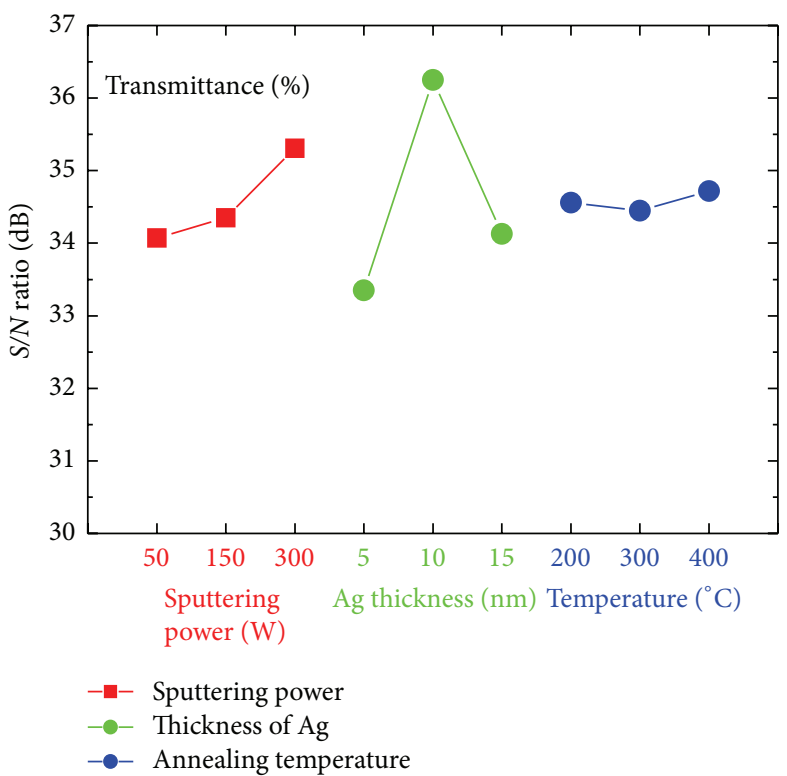

(b)

FIGURE 11: Response graphs of $S / N$ ratios for (a) resistance and (b) $T_{i}$ value at $550 \mathrm{~nm}$ for the ZAZ multilayers.

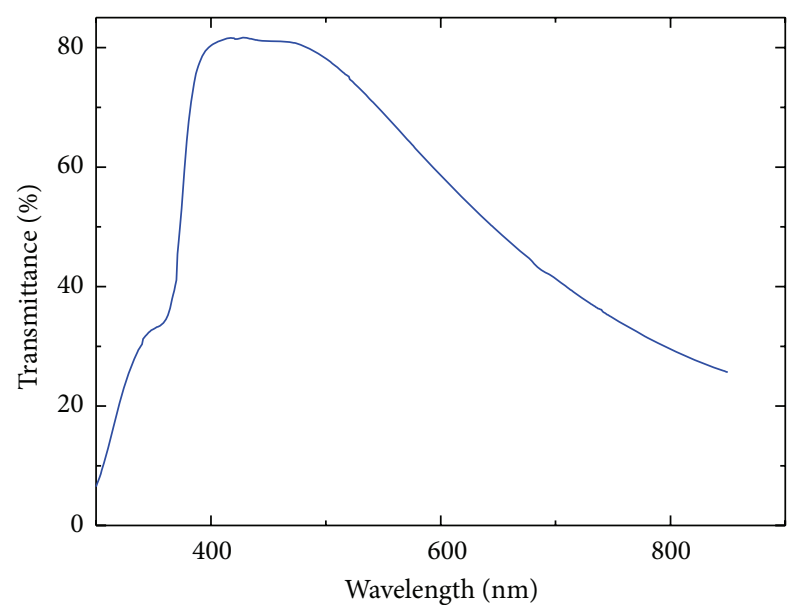

FIGURE 12: Dependence of the FOM of ZA(10)Z grown by different RF sputtering power on the PDA temperature.

$(2.3 \Omega / \mathrm{sq})$ and transmittance $(71 \%)$, the optimal FOM of the ZAZ with $1.41 \times 10^{-2} \Omega^{-1}$ can be achieved.

\section{Conclusions}

(1) Crystalline, structure, electrical, optical, and thermal stable properties for ZCZ and ZAZ stacked layers on glass with low resistance and high visible transmittance were studied. ZAZ sandwiched layer exhibits superior thermal stability than that of $\mathrm{ZCZ}$ one. The crystalline of $\mathrm{ZnO}$ and $\mathrm{Ag}$ films shows (0002) and (111) preferred orientation, respectively. The examination by HRTEM indicates that Ag was deposited with a thickness of $10 \mathrm{~nm}$ to form a continuous film. No interfacial reaction occurs between $\mathrm{ZnO}$ and $\mathrm{Ag}$ layers. An analysis of the $\mathrm{O} 1 \mathrm{~s}$ peak of $\mathrm{ZnO}$ film revealed that they are some nonlattice $\mathrm{O}$ atoms in the matrix of $\mathrm{ZnO}$. From the results of the chemical composition in the matrix of $\mathrm{ZnO}$, the $\mathrm{Ag}$ profiles remain the same for the as-prepared sample or annealed sample after PDA of $400^{\circ} \mathrm{C}, 20 \mathrm{~min}$. The resistance of the stacked layer decreases with the PDA temperature being higher than $300^{\circ} \mathrm{C}$. The improved crystalline of $\mathrm{ZnO}$ and $\mathrm{Ag}$ layer may be responsible for this result. The inserted Ag layer can effectively reduce the resistance of $\mathrm{ZnO}$ layer down to $4.17 \Omega / \mathrm{sq}$. The surface roughness of the coating increases with the temperature of PDA being higher than $200^{\circ} \mathrm{C}$; these results indicated that the scattering photon induced by free carriers may lead to the degradation of the visible transmittance properties of the $Z A Z$ layer. The highest FOM of $\mathrm{ZA}(10) \mathrm{Z}$ is $1.15 \times 10^{-2} \Omega^{-1}$ for the ZAZ sample after PDA of $200^{\circ} \mathrm{C}$ for $20 \mathrm{~min}$. The ZAZ multilayers after an appropriate PDA treatment show the potential for the application of the TCE with low $R_{s}$ and high optical transmittance.

(2) The Taguchi method with an $L_{9}$ orthogonal array was implemented to optimize the experimental parameters for this design of multilayer. The Ag thickness had the most influence on the resistance and visible transmittance. The influence of the sputtering power, however, was insignificant compared to the other factors. Through the application of Taguchi's method, the individual optimum processing conditions for the resistance and the $T_{i}$ value were obtained.

(3) To increase the FOM, a set of alternative optimal conditions was proposed, that is, a plasma power 
of $300 \mathrm{~W}$ for the first $\mathrm{ZnO} \mathrm{BL}, \mathrm{Ag}$ thickness of $10 \mathrm{~nm}$, and $400^{\circ} \mathrm{C}$ for $20 \mathrm{~min}$ of PDA. The verification experiment revealed that $\mathrm{ZAZ}$ with a low resistance of $\sim 2.3 \Omega / \mathrm{sq}$ and a high $T_{i}$ value of $71 \%$ at $550 \mathrm{~nm}$ and high FOM $\left(1.41 \times 10^{-2} \Omega^{-1}\right)$ were prepared using the processing parameters. These results were consistent with the predicted values derived from the Taguchi method.

\section{Conflict of Interests}

The authors declare that there is no conflict of interests regarding the publication of this paper.

\section{Acknowledgment}

The financial support of the National Science Council of the Republic of China (Taiwan) under Grant no. MOST 103-2221E-159-023 is gratefully acknowledged.

\section{References}

[1] J. Xu, Z. Chen, J. A. Zapien, C.-S. Lee, and W. Zhang, "Surface engineering of $\mathrm{ZnO}$ nanostructures for semiconductorsensitized solar cells," Advanced Materials, vol. 26, no. 31, pp. 5337-5367, 2014.

[2] M. Dosmailov, L. N. Leonat, J. Patek et al., "Transparent conductive $\mathrm{ZnO}$ layers on polymer substrates: thin film deposition and application in organic solar cells," Thin Solid Films, vol. 591, pp. 97-104, 2015.

[3] S. Musić, S. Popović, M. Maljković, and D. Dragčević, "Influence of synthesis procedure on the formation and properties of zinc oxide," Journal of Alloys and Compounds, vol. 347, no. 1-2, pp. 324-332, 2002.

[4] Q. Huang, Y. Wang, S. Wang, D. Zhang, Y. Zhao, and X. Zhang, "Transparent conductive ZnO:B films deposited by magnetron sputtering," Thin Solid Films, vol. 520, no. 18, pp. 5960-5964, 2012.

[5] M. V. Castro and C. J. Tavares, "Dependence of Ga-doped ZnO thin film properties on different sputtering process parameters: substrate temperature, sputtering pressure and bias voltage," Thin Solid Films, vol. 586, pp. 13-21, 2015.

[6] J. N. Alexander, N. Sun, R. Sun, H. Efstathiadis, and P. Haldar, "Development and characterization of transparent and conductive InZnO films by magnetron sputtering at room temperature," Journal of Alloys and Compounds, vol. 633, pp. 157-164, 2015.

[7] B. Deng, Q. Wei, and W. Gao, "Physical properties of Al-doped $\mathrm{ZnO}$ films deposited on nonwoven substrates by radio frequence magnetron sputtering," Journal of Coatings Technology Research, vol. 5, no. 3, pp. 393-397, 2008.

[8] T. A. Krajewski, K. Dybko, G. Luka et al., "Analysis of scattering mechanisms in zinc oxide films grown by the atomic layer deposition technique," Journal of Applied Physics, vol. 118, Article ID 035706, 2015.

[9] D. Kim, "The structural and optoelectrical properties of TiON/Au/TiON multilayer films," Materials Letters, vol. 64, no. 6, pp. 668-670, 2010.

[10] E. R. Rwenyagila, B. Agyei-Tuffour, M. G. Zebaze Kana, O. Akin-Ojo, and W. O. Soboyejo, "Optical properties of $\mathrm{ZnO} / \mathrm{Al} /$
$\mathrm{ZnO}$ multilayer films for large area transparent electrodes," Journal of Materials Research, vol. 29, no. 24, pp. 2912-2920, 2014.

[11] M. I. Ionescu, F. Bensebaa, and B. L. Luan, "Study of optical and electrical properties of $\mathrm{ZnO} / \mathrm{Cu} / \mathrm{ZnO}$ multilayers deposited on flexible substrate," Thin Solid Films, vol. 525, pp. 162-166, 2012.

[12] W. Yang, Z. Wu, Z. Liu, and L. Kong, "Deposition of Ni, Ag, and $\mathrm{Pt}$-based $\mathrm{Al}$-doped $\mathrm{ZnO}$ double films for the transparent conductive electrodes by RF magnetron sputtering," Applied Surface Science, vol. 256, no. 24, pp. 7591-7595, 2010.

[13] G. Leftheriotis, P. Yianoulis, and D. Patrikios, "Deposition and optical properties of optimised $\mathrm{ZnS} / \mathrm{Ag} / \mathrm{ZnS}$ thin films for energy saving applications," Thin Solid Films, vol. 306, no. 1, pp. 92-99, 1997.

[14] C.-C. Wu, P. S. Chen, C.-H. Peng, and C.-C. Wang, " $\mathrm{TiO}_{x} / \mathrm{Ag} /$ $\mathrm{TiO}_{x}$ multilayer for application as a transparent conductive electrode and heat mirror," Journal of Materials Science: Materials in Electronics, vol. 24, pp. 2461-2468, 2013.

[15] B. Tian, G. Williams, D. Ban, and H. Aziz, "Transparent organic light-emitting devices using a $\mathrm{MoO}_{3} / \mathrm{Ag} / \mathrm{MoO}_{3}$ cathode," Journal of Applied Physics, vol. 110, no. 10, Article ID 104507, 2011.

[16] P. Prepelita, V. Craciun, F. Garoi, and A. Staicu, "Effect of annealing treatment on the structural and optical properties of AZO samples," Applied Surface Science, vol. 352, pp. 23-27, 2015.

[17] S. Q. Chen, M. E. A. Warwick, and R. Binions, "Effects of film thickness and thermal treatment on the structural and optoelectronic properties of $\mathrm{Ga}$-doped $\mathrm{ZnO}$ films deposited by solgel method," Solar Energy Materials and Solar Cells, vol. 137, pp. 202-209, 2015.

[18] D. R. Sahu and J.-L. Huang, "High quality transparent conductive $\mathrm{ZnO} / \mathrm{Ag} / \mathrm{ZnO}$ multilayer films deposited at room temperature," Thin Solid Films, vol. 515, no. 3, pp. 876-879, 2006.

[19] D. R. Sahu, S.-Y. Lin, and J.-L. Huang, " $\mathrm{ZnO} / \mathrm{Ag} / \mathrm{ZnO}$ multilayer films for the application of a very low resistance transparent electrode," Applied Surface Science, vol. 252, no. 20, pp. 75097514, 2006.

[20] W. L. Liu, S. H. Hsieh, W. J. Chen, and J. H. Lee, "Study of nanosized Zinc Oxide on $\mathrm{Cu}-\mathrm{Zn}$ alloy substrate using Taguchi method," Surface and Coatings Technology, vol. 201, no. 22-23, pp. 9238-9242, 2007.

[21] L. F. Lai, W. J. Zeng, X. Z. Fu, R. X. Sun, and R. X. Du, “Optimization of sputtering parameters for $\mathrm{Ni}$-Cr alloy deposition on copper foil as embedded thin film resistor," Surface and Coatings Technology, vol. 218, no. 1, pp. 80-86, 2013.

[22] D. Yiamsawas, K. Boonpavanitchakul, and W. Kangwansupamonkon, "Optimization of experimental parameters based on the Taguchi robust design for the formation of zinc oxide nanocrystals by solvothermal method," Materials Research Bulletin, vol. 46, no. 5, pp. 639-642, 2011.

[23] D. Z. Segu, J.-H. Kim, S. G. Choi, Y.-S. Jung, and S.-S. Kim, "Application of Taguchi techniques to study friction and wear properties of $\mathrm{MoS}_{2}$ coatings deposited on laser textured surface," Surface \& Coatings Technology, vol. 232, pp. 504-514, 2013.

[24] G. Haacke, "New figure of merit for transparent conductors," Journal of Applied Physics, vol. 47, no. 9, pp. 4086-4089, 1976.

[25] B. D. Cullity and S. R. Stock, Elements of X-Ray Diffraction, chapter 3, Prentice-Hall, Englewood Cliffs, NJ, USA, 2001.

[26] Y. M. Lu, W. S. Hwang, W. Y. Liu, and J. S. Yang, "Effect of RF power on optical and electrical properties of $\mathrm{ZnO}$ thin film by magnetron sputtering," Materials Chemistry and Physics, vol. 72, no. 2, pp. 269-272, 2001. 
[27] N. Xu, L. F. Liu, X. Sun et al., "Characteristics and mechanism of conduction/set process in TiN/ZnO/Pt resistance switching random-access memories," Applied Physics Letters, vol. 92, no. 23, Article ID 232112, 3 pages, 2008.

[28] Y. C. Yang, F. Pan, F. Zeng, and M. Liu, "Switching mechanism transition induced by annealing treatment in nonvolatile $\mathrm{Cu} / \mathrm{ZnO} / \mathrm{Cu} / \mathrm{ZnO} / \mathrm{Pt}$ resistive memory: from carrier trapping/detrapping to electrochemical metallization," Journal of Applied Physics, vol. 106, no. 12, Article ID 123705, 2009.

[29] S. H. Mohamed, "Effects of Ag layer and $\mathrm{ZnO}$ top layer thicknesses on the physical properties of $\mathrm{ZnO} / \mathrm{Ag} / \mathrm{Zno}$ multilayer system," Journal of Physics and Chemistry of Solids, vol. 69, no. 10, pp. 2378-2384, 2008.

[30] R. Pandey, B. Angadi, S. K. Kim, J. W. Choi, D. K. Hwang, and W. K. Choi, "Fabrication and surface plasmon coupling studies on the dielectric/Ag structure for transparent conducting electrode applications," Optical Materials Express, vol. 4, no. 10, pp. 20782089, 2014.

[31] D. R. Lide, CRC Handbook of Chemistry and Physics, CRC Press, Boca Raton, Fla, USA, 76th edition, 1995.

[32] S. H. Oh, S.-M. Lee, and K. C. Choi, "Relationship between surface plasmon and transmittance enhancement in indium-tinoxide/Ag/indium-tin-oxide multilayer electrodes," Thin Solid Films, vol. 520, no. 9, pp. 3605-3608, 2012. 

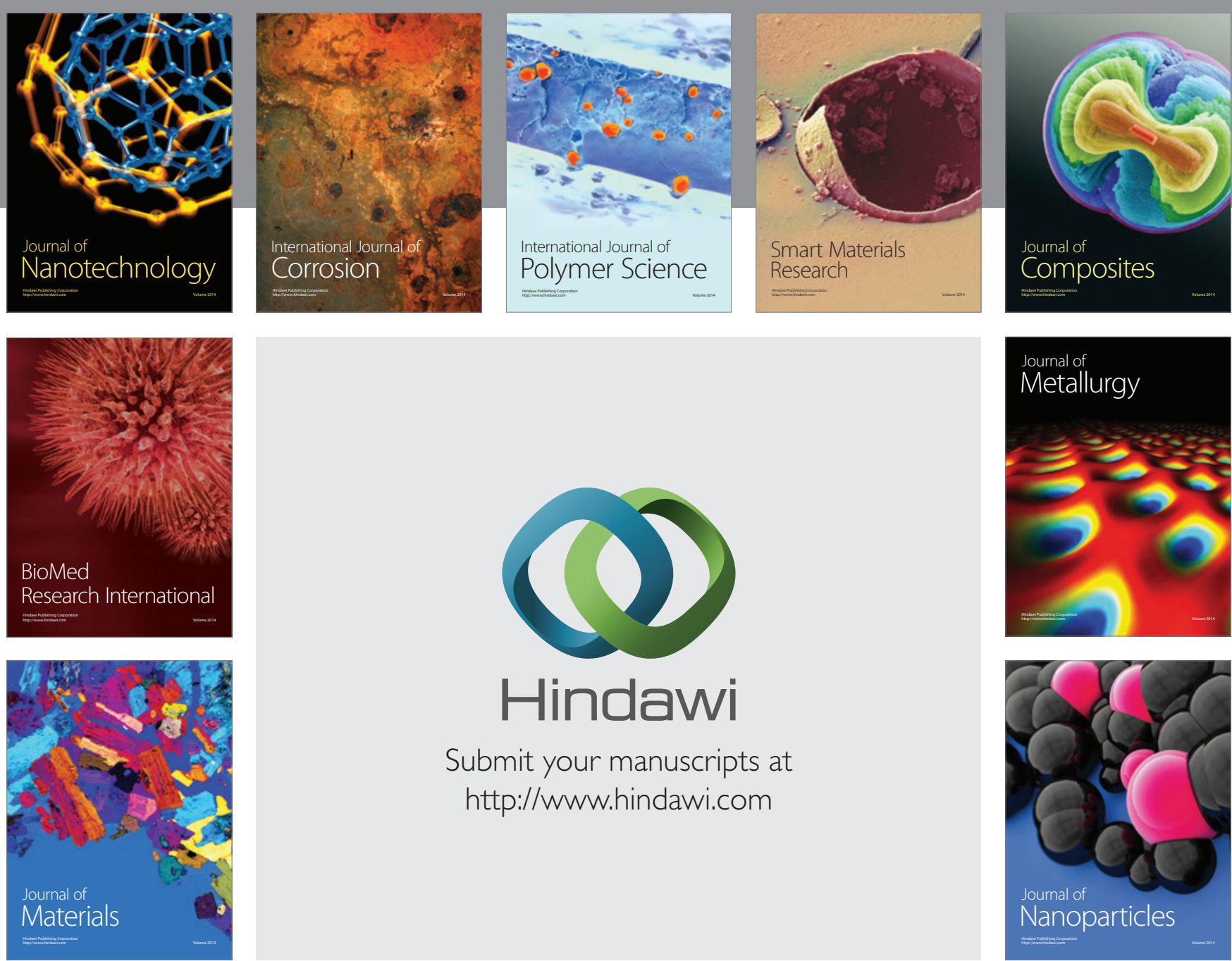

\section{Hindawi}

Submit your manuscripts at

http://www.hindawi.com

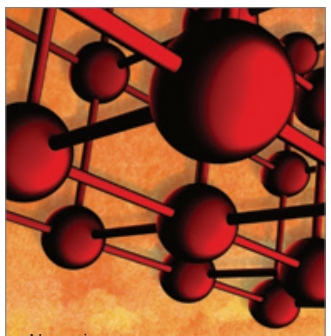

Materials Science and Engineering
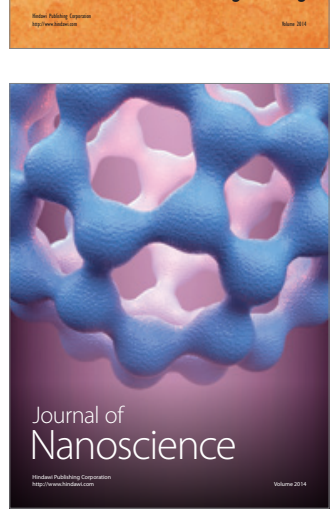
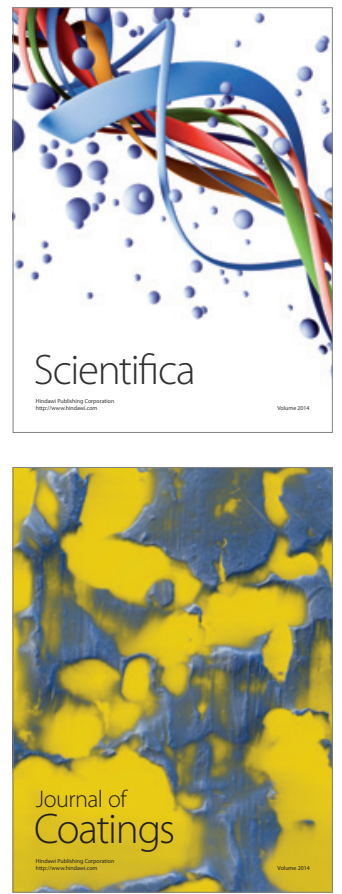
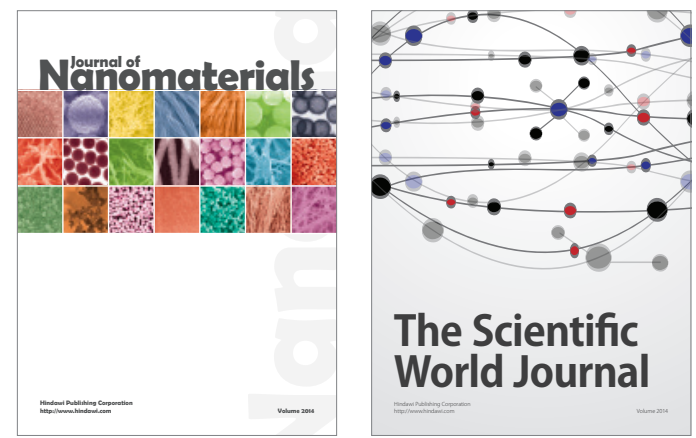

The Scientific World Journal
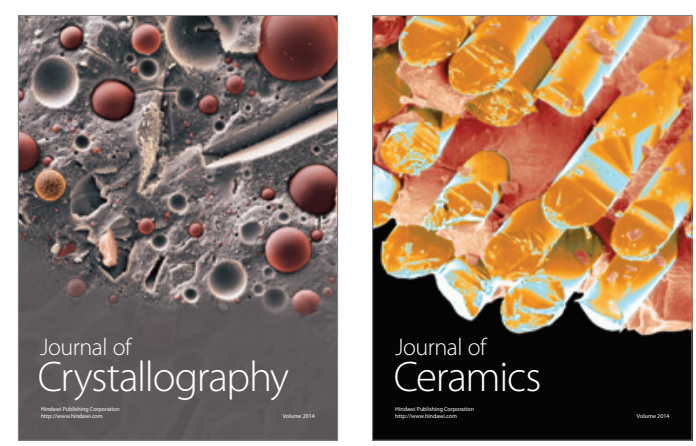
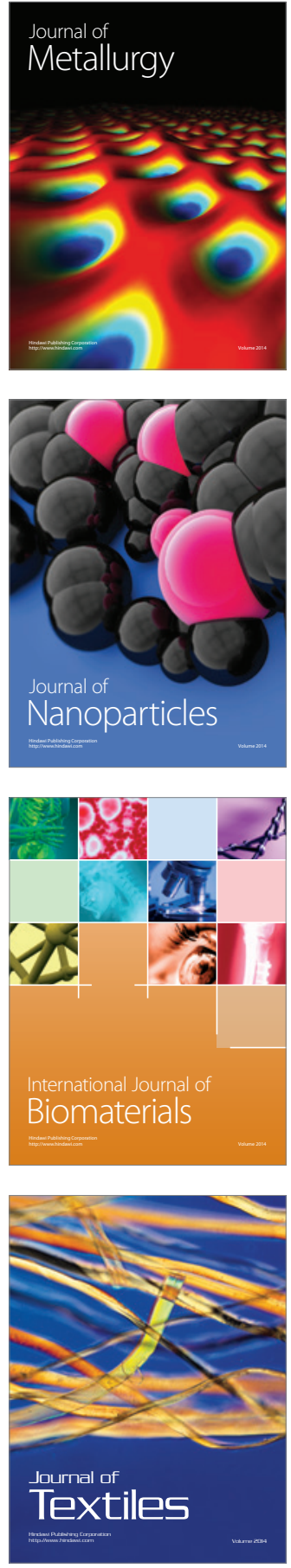